\title{
ПРАКТИЧЕСКИЕ РЕКОМЕНДАЦИИ ПО ПРОФИЛАКТИКЕ И ЛЕЧЕНИЮ
} ТРОМБОЭМБОЛИЧЕСКИХ ОСЛОЖНЕНИЙ У ОНКОЛОГИЧЕСКИХ БОЛЬНЫХ

Коллектив авторов: Сомонова О.В., Антух Э.А., Долгушин Б.И., Елизарова А.Л., Сакаева Д.Д., Сельчук В.Ю., Трякин А.А., Черкасов В.А.

DOI: $10.18027 / 2224-5057-2020-10-3 s 2-47$

Ключевые слова: онкология, тромбоэмболические осложнения, низкомолекулярные гепарины, гепарин натрия, фондапаринукс, прямые оральные антикоагулянты

Венозные тромбоэмболические осложнения (ВТЭО) - собирательное понятие, объединяющее тромбоз поверхностных вен, тромбоз глубоких вен, венозную гангрену и тромбоэмболию легочной артерии. ВТЭО развиваются у 10-20\% онкологических больных при жизни и выявляются при аутопсии в 30-50\% случаев.

\section{1. ФАКТОРЫ РИСКА}

Согласно классификации, у онкологических больных выделяют факторы риска развития тромботических осложнений, связанные с опухолью, с пациентом и с лечением.

Факторы риска, связанные с опухолью: локализация и гистологический тип опухоли (наиболее часто тромбозы развиваются у больных раком поджелудочной железы, желудка, легких, яичников, почек, головного мозга, миеломе, лимфоме); стадия (поздняя); длительность заболевания (менее 3 месяцев); биомаркеры (высокий уровень Д-димера, фибриногена, фибрин-мономера, Р-селектина, С-реактивного белка, тканевого фактора).

Факторы риска, связанные с пациентом (табл. 1):

Цитирование: Сомонова О.В., Антух Э.А., Долгушин Б.И., Елизарова А.Л., Сакаева Д.Д., Сельчук В.Ю. и соавт. Практические рекомендации по профилактике и лечению тромбоэмболических осложнений у онкологических больных. Злокачественные опухоли: Практические рекомендации RUSSCO \#3s2, 2020 (том 10).47 
Таблица 1. Факторы риска венозных тромбоэмболических осложнений

\begin{tabular}{|c|c|}
\hline \multicolumn{2}{|l|}{ Факторы риска } \\
\hline \multirow{2}{*}{ 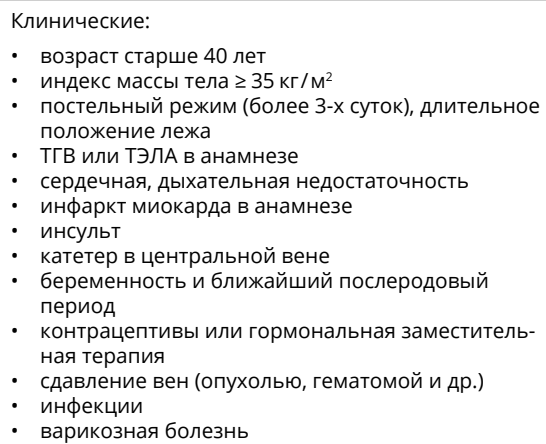 } & $\begin{array}{l}\text { Гемостазиологические признаки гиперкоагуляции: } \\
\text { • } \text { фибриноген > } 400 \text { мг/мл } \\
\text { - Д-димер > 0,5 мкг/мл }\end{array}$ \\
\hline & $\begin{array}{l}\text { Другие: } \\
\text { - } \quad \text { количество тромбоцитов }>350 \times 10^{9} / л \\
\text { - } \text { количество лейкоцитов }>11 \times 10^{9} / л \\
\text { - гемоглобин < } 100 \text { г/л } \\
\text { - } \text { лечение эритропоэтином }\end{array}$ \\
\hline
\end{tabular}

Факторы риска, связанные с лечением: операция (лапаротомия или лапароскопия продолжительностью более 30 минут, открытые операции на органах брюшной полости и малого таза); химиотерапия; лучевая терапия; катетерассоциированные вмешательства (центральный, бедренный, периферический венозный катетер).

\section{2. ДИАГНОСТИКА}

\section{1. Лабораторная диагностика}

2.1.1.У пациентов перед хирургическим вмешательством рекомендуется проведение лабораторных тестов, минимальный объем которых включает: определение концентрации фибриногена, АЧТВ, протромбинового времени. Расширенная диагностическая панель может включать определение уровня Д-димера.

2.1.2. У пациентов, получающих противоопухолевую лекарственную терапию. Перед началом первого курса противоопухолевой лекарственной терапии рекомендуется проведение лабораторных тестов, минимальный объем которых включает: определение концентрации фибриногена, АЧТВ, протромбинового времени. Расширенная диагностическая панель может включать определение уровня Д-димера.

В процессе противоопухолевой лекарственной терапии рутинный лабораторный контроль не рекомендуется.

2.1.3. Пациентам с клиническими признаками, позволяющими заподозрить ВТЭО, при отсутствии возможности выполнить в ближайшие часы компрессионное ультразвуковое ангиосканирование рекомендуется определить уровень Д-димера. В случае низкого уровня Д-димера диагноз ВТЭО можно отвергнуть с высокой степенью вероятности. Повышение этого показателя свидетельствует о необходимости проведения ультразвукового исследования. 


\section{2. Инструментальная диагностика}

Больным рекомендуется выполнять ультразвуковое ангиосканирование (УЗАС) бассейна нижней полой вены перед операцией для выявления бессимптомных венозных тромбозов, с максимальным приближением исследования ко времени вмешательства. Также рекомендуется выполнение УЗАС бассейна нижней полой вены в послеоперационном периоде перед активизацией больного, если профилактические мероприятия выполнялись не в полном объеме.

\section{3. ЛЕЧЕНИЕ}

\section{1. Консервативное лечение венозных тромбозмболических осложнений у онкологических больных}

\subsection{1. Острая стадия}

Рекомендуется начинать лечение с назначения низкомолекулярных гепаринов, гепарина натрия или фондапаринукса.

Таблица 2. Перечень антикоагулянтов, рекомендуемых для лечения острого тромбоза

\begin{tabular}{|c|c|c|}
\hline Препараты & Дозы антикоагулянтов, п/к & Режимы введения \\
\hline $\begin{array}{l}\text { Низкомолекулярные гепарины: } \\
\text { - далтепарин натрия } \\
\text { · надропарин кальция } \\
\text { - надропарин кальция форте } \\
\text { (фраксипарин форте) } \\
\text { · эноксапарин натрия }\end{array}$ & $\begin{array}{l}\text { - } 100 \mathrm{ME} / \text { кг } 2 \text { раза в сутки } \\
\text { - } 200 \mathrm{ME} / \text { кг } 1 \text { раз в сутки } \\
\text { - } 86 \mathrm{ME} / \text { кг } 2 \text { раза в сутки } \\
\text { - } 172 \mathrm{ME} / \text { кг } 1 \text { раз в сутки } \\
\text { - } 172 \mathrm{ME} / \text { кг } 1 \text { раз в сутки } \\
\text { - } 100 \mathrm{ME} / \text { кг } 2 \text { раза в сутки } \\
\text { - } 150 \mathrm{ME} / \text { кг } 1 \text { раз в сутки }\end{array}$ & 10-14 дней \\
\hline Гепарин натрия & $\begin{array}{l}\text { болюс в/в } 80 \text { МЕ/кг и инфузия } \\
\text { со скоростью } 18 \text { МЕ/кг в час } \\
\text { до целевых значений АЧТВ } \\
\text { в 1,5-2,5 раза выше нормы } \\
\text { в вутривенно болюсно } 5000 \text { МЕ, } \\
\text { затем } 150 \text { МЕ/кг } 3 \text { раза в сутки }\end{array}$ & 5-7 дней \\
\hline Фондапаринукс натрия & - 5-10 мг 1 раз в сутки & 5-9 дней \\
\hline
\end{tabular}

1 Низкомолекулярные гепарины и гепарин натрия вводятся в дозе, соответствующей массе тела; при назначении гепарина натрия АЧТВ должно увеличиться в 1,5-2,5 раза от своего исходного уровня, после чего следует продолжить лечение с использованием АВК (варфарин под контролем МнО на уровне 2-3) или низкомолекулярными гепаринами. Следует учитывать наличие противопоказаний. У больных с почечной недостаточностью (клиренс креатинина <25-30 мл/мин.) при назначении НМГ или гепарина натрия необходим мониторинг анти-Ха активности. Низкомолекулярный гепарин далтепарин натрия безопасен при нарушении функции почек вследствие отсутствия биоаккумуляции и не требует коррекции профилактической дозы. При тромбоцитопении (<100×10\%/л) дозу НМГ следует уменьшить, а при числе тромбочитов менее 50×10\%/л препарат отменить. Фондапаринукс натрия не взаимодействует с тромбоцитами и не вызывает гепарин-индуцированную тромбоцитопению в отличие от НМГ и гепарина натрия и более безопасен упациентов с низким уровнем тромбоцитов. 
Длительность первоначального лечения антикоагулянтами (преимущественно низкомолекулярными гепаринами) должна составлять не менее 90-180 дней. Низкомолекулярные гепарины безопасны и более эффективны для лечения тромботических осложнений по сравнению с антагонистами витамина К, так как существенно снижают риск рецидива ВТЭО. Решение о продлении терапии следует принимать индивидуально с учетом проводимого лекарственного лечения, наличия дополнительных факторов риска развития тромботических осложнений при низком риске кровотечения.

Эффективность антикоагулянтной терапии определяется уровнем маркера внутрисосудистого свертывания крови (Д-димера) и результатами дуплексного ангиосканирования (наличие или отсутствие тромбоза). При высоком уровне Д-димера (> 2 мкг/мл) антикоагулянтную терапию необходимо продолжить.

\subsection{2. Антикоагулянтная терапия у больных с рецидивом венозного тромбоэмболического осложнения}

При рецидиве тромбоэмболического осложнения на фоне длительной терапии АВК с МНО в пределах субтерапевтических значений (<2) рекомендуется возобновить лечение гепарином натрия, или НМГ, или фондапаринуксом натрия, а затем - АВК с поддержанием уровня $\mathrm{MHO}=2-3$. При рецидиве тромбоэмболического осложнения у больного, длительно получающего АВК при значении $\mathrm{MHO}=2-3$, необходимо: 1) выбрать другой метод антикоагулянтной терапии (низкомолекулярные гепарины, или гепарин натрия, или фондапаринукс натрия) или 2) изменить дозу антагониста витамина К с целью увеличения МНО до 3,5. При рецидиве тромбоэмболического осложнения у больного, получающего терапевтические дозы НМГ, необходимо увеличить дозу НМГ на 20-25\%, или перевести больного на фондапаринукс натрия, или имплантировать кавафильтр в дополнение к лечению НМГ.

\subsection{3. Лечение катетер-ассоциированного тромбоза}

Это осложнение рекомендуется лечить преимущественно низкомолекулярными гепаринами. Длительность первоначального лечения антикоагулянтами должна составлять не менее 90 дней.

Решение об удалении катетера принимается индивидуально. В большинстве случаев катетер приходится удалять.

\subsection{4. Прямые оральные антикоагулянты (ПОАК) для лечения и вторичной профилактики венозных тромбоэмболических осложнений у онкологических больных}

В настоящее время интенсивно изучается возможность применения ПОАК для лечения и вторичной профилактики ВТЭО в онкологии. По данным ряда исследований, их эффективность сопоставима с эффективностью НМГ, однако ассоциирована с несколько большим риском возникновения кровотечений. У пациентов, которые отказываются от приема или имеют веские причины 
избегать применения НМГ, препаратом выбора для лечения ТГВ/ТЭЛА могут быть прямые оральные антикоагулянты (табл. 3). Среди зарегистрированных на территории РФ ПОАК только для апиксабана и ривароксабана проводились отдельно спланированные исследования у онкологических больных. Апиксабан и ривароксабан рекомендуются в качестве одного из вариантов терапии пациентов с онкоассоциированными тромбозами при низком риске кровотечения и отсутствии лекарственных взаимодействий с текущей системной терапией. В соответствии с инструкцией по медицинскому применению продленную терапию возможно проводить апиксабаном 2,5 мг 2 раза в сутки и ривароксабаном в дозах как 20 мг так и 10 мг 1 раз в сутки.

таблица 3. Рекомендуемые прямые оральные антикоагулянты для лечения венозных тромбоэмболических осложнений у онкологических больных

\begin{tabular}{|l|l|l|l|}
\hline & Острая фаза (5-7 дней) & $\begin{array}{l}\text { Длительная } \\
\text { терапия (3-6 мес.) }\end{array}$ & $\begin{array}{l}\text { Продолженная } \\
\text { профилактика (> 6 мес.) }\end{array}$ \\
\hline Апиксабан & $\begin{array}{l}\text { По } 10 \text { мг 2 раза в сутки, } \\
7 \text { дней }\end{array}$ & По 5 мг 2 раза в сутки & По 2,5 мг 2 раза в сутки \\
\hline $\begin{array}{l}\text { Дабигатран этекси- } \\
\text { лат (после началь- } \\
\text { ной терапии НМг } \\
\text { в течение 7 дней) }\end{array}$ & $\begin{array}{l}\text { По 150 мг 2 раза в сутки; } \\
\text { минимальная длитель- } \\
\text { ность приема - 5 дней }\end{array}$ & По 150 мг 2 раза в сутки & По 150 мг 2 раза в сутки \\
\hline Ривароксабан & $\begin{array}{l}\text { По 15 мг 2 раза в сутки, } \\
21 \text { день }\end{array}$ & По 20 мг 1 раз в сутки & $\begin{array}{l}\text { По 20 мг 1 раз в сутки или } \\
10 \text { мг в сутки }\end{array}$ \\
\hline
\end{tabular}

ПОАК следует осторожно применять в комбинации с препаратами, подавляющими активность СҮРЗА4 и Р-гликопротеина (иматиниб, кризотиниб, абиратерон, энзулатамид, циклоспорин, такролимус) или повышающими активность СҮРЗА4 и Р-гликопротеина (паклитаксел, вемурафениб, дазатиниб, циклоспорин, такролимус), поскольку при этом изменяется фармакокинетика ПОАК (см. рис. 1).

\section{4. РЕАБИЛИТАЦИЯ}

Необходима коррекция образа жизни (изменение условий труда, увеличение динамической активности, уменьшение вертикальной нагрузки, ограничение тяжелой физической нагрузки, дозированная лечебная ходьба, регулярная разгрузочная гимнастика, плавание), а также:

- коррекция массы тела;

- лечебная физкультура;

- ношение компрессионного трикотажа;

- назначение венотоников;

- местное лечение трофических поражений. 


\section{5. ПРОФИЛАКТИКА И ДИСПАНСЕРНОЕ НАБЛЮДЕНИЕ}

\section{1. Профилактика венозных тромбоэмболических осложнений у хирургических больных}

Все стационарные онкологические больные должны рассматриваться в качестве кандидатов для антикоагулянтной профилактики венозных тромбоэмболических осложнений (ВТЭО) при отсутствии кровотечений или других противопоказаний. Факт госпитализации повышает риск ВТЭО за счет снижения двигательной активности.

\subsection{1. Медикаментозные способы профилактики}

Больным, подвергшимся оперативному вмешательству продолжительностью более 30 мин рекомендуется антитромботическая профилактика. Следует использовать низкомолекулярные гепарины, нефракционированный гепарин или фондапаринукс натрия (табл. 4). Продолжительность профилактики различна:

- после лапаротомии, лапароскопии, торакотомии или торакоскопии продолжительностью более 30 минут длительность профилактики тромботических осложнений должна быть не менее 7-10 дней;

- после обширных оперативных вмешательств, особенно на органах брюшной полости и малого таза, а также при наличии дополнительных факторов риска, рекомендуемая длительность профилактики ВТЭО составляет 28 дней.

Таблица 4. Перечень антикоагулянтов, рекомендуемых в послеоперационном периоде

\begin{tabular}{|c|c|c|}
\hline Препараты & Дозы антикоагулянтов, п/ ${ }^{1,4,5}$ & Режимы введения ${ }^{2,3}$ \\
\hline $\begin{array}{l}\text { Низкомолекулярные } \\
\text { гепарины: } \\
\text { • далтепарин натрия } \\
\text { • надропарин кальция } \\
\text { • эноксапарин натрия }\end{array}$ & $\begin{array}{l}5000 \text { МЕ анти-Ха активности } 1 \text { раз в сутки } \\
2850-5700 \text { МЕ анти-Ха активности } 1 \text { раз } \\
\text { в сутки } \\
4000 \text { МЕ, } 5000 \text { МЕ анти-Ха активности } \\
1 \text { раз в сутки }\end{array}$ & \multirow{3}{*}{$\begin{array}{l}\text { За } 12 \text { часов до операции и далее } \\
\text { с первых суток послеоперацион } \\
\text { ного периода } \\
\\
\text { Через 6-24 часа после операции }\end{array}$} \\
\hline Гепарин натрия & 5000 ЕД 3 раза в сутки & \\
\hline Фондапаринукс натрия 6 & 2,5 мг 1 раз в сутки & \\
\hline
\end{tabular}

1 Доза антикоагулянта подбирается индивидуально в зависимости от массы тела и дополнительных факторов риска; профилактика проводится под контролем коагулограммы; доза иэффективность антикоагулянтной профилактики определяется уровнем маркера внутрисосудистого свертывания крови (Д-димера); при высоком уровне Д-димера (> 2 мкг/мл) дозу антикоагулянта следует увеличить.

2 При наличии дополнительных факторов риска (см. табл. 1) профилактика тромботических осложнений может начинаться за 5-7 дней до операции.

3 В раннем послеоперационном периоде необходимо учитывать риск развития кровотечения. Привысоком риске кровотечения начинать антитромботическую профилактику можно с 2-3 суток после операции.

4 У пациентов с тяжелой почечной недостаточностью доза НМГ может быть уменьшена в 2 раза.

5 У пациентов с низкой массой тела дозу нМГ следует уменьшить в 2 раза, аулиц с массой тела больше 120 кг увеличить в 1,5 раза. 
6 Фондапринукс натрия не взаимодействует с тромбоцитами и не вызывает гепарин-индуцированную тромбоцитопению в отличие от НМГ и гепарина натрия и более безопасен у пациентов с низким уровнем тромбоцитов.

\subsection{2. Механические способы профилактики}

Механические способы являются дополнением к медикаментозным методам. К механическим способам профилактики относятся:

- ношение эластичных чулок, обеспечивающих оптимальное распределение давления на нижние конечности;

- эластическое бинтование;

- перемежающаяся пневматическая компрессия нижних конечностей;

- венозный насос для стопы.

\section{2. Профилактика венозных тромбоэмболических осложнений в процессе противоопухолевой лекарственной терапии}

Рутинное проведение антикоагулянтной профилактики ВТЭО у пациентов, получающих противоопухолевую лекарственную терапию, не рекомендуется.

- Решение о проведении фармакопрофилактики ВТЭО принимается индивидуально на основе оценки соотношения пользы и риска развития кровотечения. Факторами высокого риска развития ВТЭО, при которых в отсутствие противопоказаний рекомендуется проведение профилактики ВТЭО, являются $\geq 3$ по шкале A. A. Khorana (табл. 5); длительная иммобилизация, клинически значимая активная инфекция; компрессия опухолью крупных вен; герминогенная опухоль яичка с метастазами в забрюшинные лимфоузлы размерами свыше 5 см; местнораспространенный или метастатический рак поджелудочной железы; местнораспространенный или метастатический рак легких; злокачественные опухоли головного мозга, уровень Д-димера.

- Антитромботическая профилактика рекомендуется больным множественной миеломой, получающих талидомид или леналидомид в сочетании с химиотерапией и/или дексаметазоном.

Рекомендуется с целью профилактики ВТЭО использовать низкомолекулярные гепарины или ПОАК (апиксабан, ривароксабан). При высоком риске кровотечения ${ }^{1}$ или клинически значимых лекарственных взаимодействиях ПОАК с текущей системной терапией² предпочтительным является применение низкомолекулярных гепаринов (табл. 6).

1 у больных с высоким риском кровотечения (пациенты с опухолями верхних отделов желудочно-кишечного тракта и мочеполовой системы, больные с нефростомами, чентральным венозным катетером, эрозивно-язвенными поражениями желудочно-кишечного тракта, заболеваниями печени, тромбочитопенией, СКФ 15-29 мл/мин) предпочтительнее НМГ.

2 ПОАК следует осторожно применять в комбинации с препаратами, подавляющими активность СҮРЗА4 и Р-гликопротеина (иматиниб, кризотиниб, абиратерон, энзулатамид, чиклоспорин, такролимус) или повышающими активность СҮРЗА4 и Р-гликопротеина (паклитаксел, вемурафениб, дазатиниб, циклоспорин, такролимус), поскольку при этом изменяется фармакокинетика ПОАК. 
Таблица 5. Шкала Khorana для прогнозирования риска развития ВТЭО у онкологических больных, получающих противоопухолевую лекарственную терапию

\begin{tabular}{|c|c|}
\hline Фактор риска & Баллы \\
\hline $\begin{array}{l}\text { Локализация опухоли (первичный очаг): } \\
\text { • очень высокий риск (поджелудочная железа, желудок) } \\
\text { • высокий риск (легкое, лимфа, гинекология, мочевой пузырь, яичко) }\end{array}$ & $\begin{array}{l}2 \\
1\end{array}$ \\
\hline Количество тромбоцитов до химиотерапии $\geq 350 \times 10^{9} / л$ & 1 \\
\hline Концентрация гемоглобина < 100 г/л или применение эритропоэтина & 1 \\
\hline Количество лейкоцитов до химиотерапии > $11 \times 10^{9} / л$ & 1 \\
\hline Индекс массы тела (ИМТ) $\geq 35$ кг/м² & 1 \\
\hline $\begin{array}{l}\text { Вероятность развития ТГВ и ТЭЛА } \\
\text { - } \text { низкий риск } \\
\text { - умеренный риск } \\
\text { - } \text { высокий риск }\end{array}$ & $\begin{array}{l}0 \\
1-2 \\
3\end{array}$ \\
\hline
\end{tabular}

Вероятность развития тромбоза у пациентов с низким риском по шкале Khorana, составляет 0,3-1,5\%, с умеренным риском - 1,8-4,8\%, а с высоким $6,7-12,9 \%$.

Таблица 6. Перечень антикоагулянтов, рекомендуемых в процессе противоопухолевой лекарственной терапии с целью первичной профилактики ВТЭО

\begin{tabular}{|c|c|c|}
\hline Препараты & Дозы антикоагулянтов, п/к & Режимы введения \\
\hline $\begin{array}{l}\text { Низкомолекулярные гепарины: } \\
\text { • далтепарин натрия } \\
\text { · надропарин кальция } \\
\text { • эноксапарин натрия }\end{array}$ & $\begin{array}{l}5000 \text { МЕ анти-Ха активности } 1 \text { раз в сутки } \\
2850-5700 \text { МЕ анти-Ха активности } 1 \text { раз } \\
\text { в сутки } \\
4000 \text { МЕ, } 5000 \text { МЕ анти-Ха } \\
\text { активности } 1 \text { раз в сутки }\end{array}$ & $\begin{array}{l}\text { За } 2 \text { часа до начала терапии, } \\
\text { в течение всего курса } \\
\text { противоопухолевой тера- } \\
\text { пии (в среднем } 1-14 \text { дней) } \\
\text { и 1-2 дня после окончания } \\
\text { каждого курса лечения }\end{array}$ \\
\hline $\begin{array}{l}\text { ПОАК: } \\
\text { • } \quad \text { апиксабан } \\
\text { • } \quad \text { ривароксабан }\end{array}$ & $\begin{array}{l}\text { по 2,5 мг } 2 \text { раза в сутки } \\
\text { по } 10 \text { мг } 1 \text { раз в сутки }\end{array}$ & $\begin{array}{l}\text { Непрерывно на фоне прово- } \\
\text { димой противоопухолевой } \\
\text { лекарственной терапии } \\
\text { и в течение двух недель } \\
\text { после ее завершения }\end{array}$ \\
\hline
\end{tabular}

1 Доза антикоагулянта подбирается индивидуально в зависимости от массы тела, дополнительных факторов риска. Антикоагулянтную профилактику целесообразно продолжать в течение 30 дней и более при наличии дополнительных факторов риска надропарин. Необходимо учитывать риск развития кровотечении. При массе тела <50 кг и высоком риске кровотечения следует применять над-ропарин кальция в дозе 2850 МЕ анти-Ха активности, далтепарин натрия - в дозе 2500 МЕ анти-Ха активности, эноксапарин натрия - в дозе 2000 МЕ или 3000 МЕ анти-Ха активности, апиксабан -в дозе 2,5 мг 2 раза в сутки, ривороксабан - в дозе 10 мг в сутки.

2 у амбулаторных больных, получающих химиотерапию по поводу множественной миеломы и имеющих не очень высокий риск ВТЭО, связанный с характером противоопухолевого лечения или наличием у больного дополнительных факторов риска ВТЭО, для профилактики рекомендуется использовать ацетилсалициловую кислоту в дозе 81-325 мг/сутки. 


\section{3. Профилактика венозных тромбоэмболических осложнений в процессе лучевой терапии}

Антитромботическая профилактика рекомендуется онкологическим больным, получающим лучевую терапию при наличии дополнительных факторов риска (необходим индивидуальный подход к оценке риска). Принципы антитромботической профилактики аналогичны таковым для больных, получающих противоопухолевую лекарственную терапию. Следует использовать низкомолекулярные гепарины или ПОАК в случае отказа пациента от НМГ (см. табл. 6).

\section{4. Имплантация кавафильтра в нижнюю полую вену как мера профилактики ТЭЛА у онкологических больных}

Современные кавафильтры являются атромбогенными и обладают высокими фильтрационными свойствами, случаев прохождения через них клинически опасных тромбоэмболов не отмечено. Вместе с тем кавафильтры не являются препятствием для распространения тромбов, а лишь задерживают тромбоэмболы.

Показаниями для имплантации кавафильтра онкологическим больным являются:

- $\quad$ рецидивирующая ТЭЛА, несмотря на применение терапевтических доз антикоагулянтов;

- невозможность адекватной антикоагулянтной терапии (существующее кровотечение или глубокая и продолжительная тромбоцитопения);

- эмболоопасный тромб проксимальной локализации (в бедренной, подвздошной и нижней полой вене);

- острый тромбоз глубоких вен нижних конечностей и таза перед хирургическим лечением;

- наличие тромбоза глубоких вен нижних конечностей и таза у диссеминированных больных, получающих лечение по поводу онкологического заболевания (рис. 2).

Имплантация кавафильтра онкологическому больному не показана в следующих случаях:

- двусторонний подвздошно-бедренный венозный тромбоз у больных с окклюзией верхней полой вены или с воспалительными процессами в области шеи, когда нет доступа для выполнения вмешательства;

- распространение тромбоза до уровня впадения печеночных вен и выше 1 .

1 При использовании кавафильтров нового поколения, которые не являются источником тромбообразования (не тромбируются), сепсис не является противопоказанием. 


\section{5. Диспансерное наблюдение}

После успешно проведенного противоопухолевого лечения, особенно у пациентов с тромбозами в анамнезе, необходимо определять уровень Д-димера и делать УЗАС вен с интервалом 3-6 месяцев.

\section{ПриЛОЖеНИе. АЛГОРИТМЫ ВЕДЕНИЯ ПАЦИЕНТА}

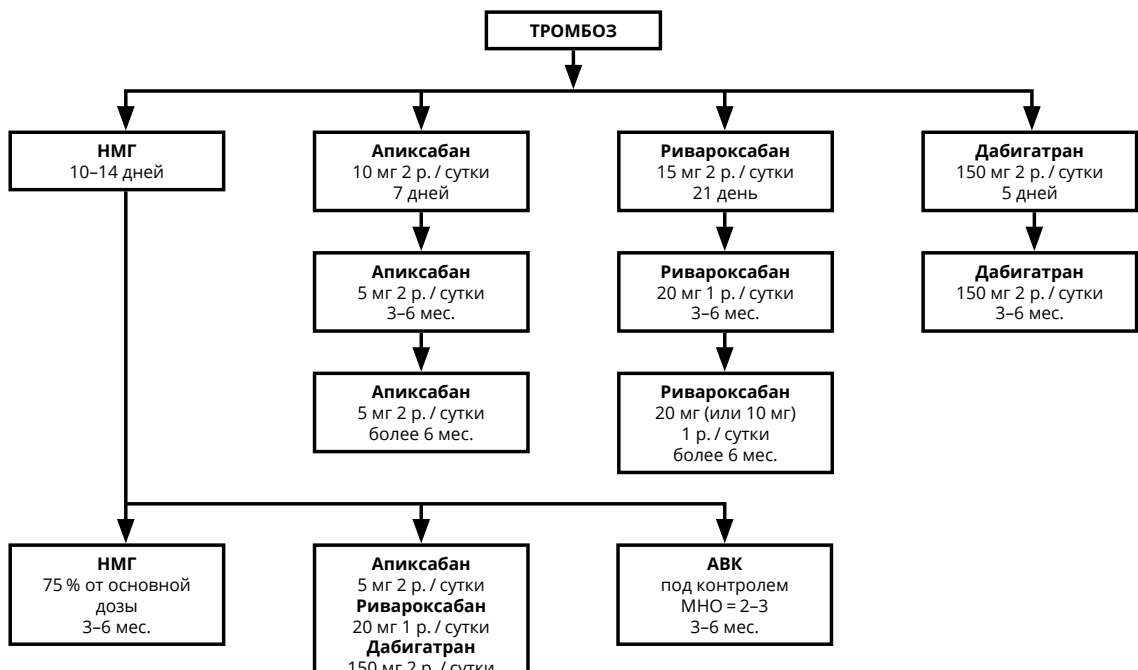

Рисунок 1. Лечения ВТЭО и профилактика рецидивов у онкологических больных.

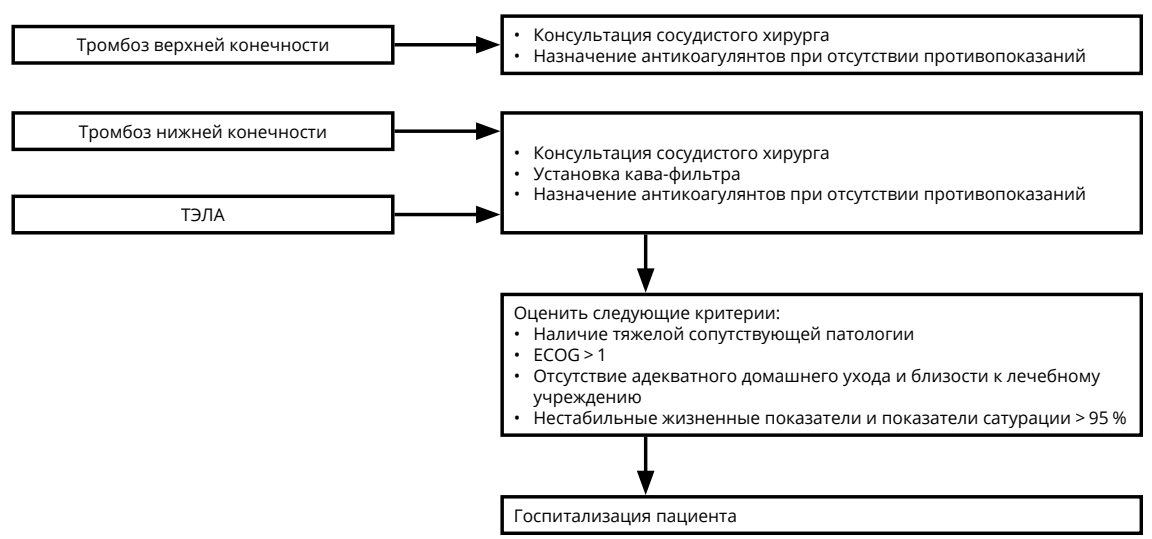

Рисунок 2. Тактика врача при развитии ВТэО. 